\title{
The Macro-Level Drivers of Intimate Partner Violence: New Evidence from a Multilevel Dataset
}

\author{
Author: Roxanne J. Kovacs \\ University Affiliation: London School of Hygiene and Tropical Medicine \\ Address: 15-17 Tavistock Place Kings Cross, WC1H 9SH London, UK \\ Phone number: 07754096462 \\ Email address: roxanne.kovacs@1shtm.ac.uk
}

\begin{abstract}
This study uses multi-level regression analysis to determine the impact of macrolevel drivers on intimate partner violence. It argues that we need to look beyond the usual, individual-level risk factors in order to understand why women experience abuse at the hands of their intimate partners. Using Demographic and Health Survey data from 40 developing countries, this paper demonstrates that socio-economic development, beliefs and laws play an important role in explaining intimate partner violence.
\end{abstract}

Keywords: violence against women, domestic violence, intimate partner violence, multilevel analysis 


\section{Introduction}

Intimate partner violence (IPV), refers to abuse taking place between current or former intimate partners (husbands, wives, boyfriends, girlfriends) (Jewkes 2002). This abuse can be physical, sexual or emotional, as well as any combination of the three. Even though comparable cross-country data on IPV is relatively scarce, the data that does exist indicates shocking prevalence rates (Stoeckl et al. 2014;). A recent review of 185 population-based studies in 86 countries estimates lifetime prevalence of sexual and physical IPV to lie at around 30\% (Garcia-Moreno et al. 2013). Similarly, evidence from the WHO Multi-country Study on Women's Health and Domestic Violence against Women, which was conducted in 10 countries, indicates a lifetime physical and sexual IPV prevalence rate of $13 \%$ to $61 \%$ (Stoeckl et al. 2014).

Numerous studies carried out in high as well as low-income countries have linked IPV to acute physical sexual and mental health problems including digestive disorders, severe headaches, pain syndromes, miscarriages, sexually-transmitted infections, anxiety and depression (Campbell et al. 2002; Johri et al. 2011; Ludermir et al. 2008; Garcia-Moreno et al. 2013). Preventing and responding to IPV is therefore an important public health concern.

The vast majority of quantitative studies that analyse the drivers of IPV have focused exclusively on individual-level risk factors (see for example, Abramsky et al. 2011; Stoeckl et al. 2014). However, whether or not a woman will experience IPV is not solely determined by her own characteristics, the characteristics of her partner, or their relationship (i.e. individual-level factors). As this paper will show, IPV is the outcome of factors that operate on multiple levels and macro-level as well as microlevel drivers play an important role. Even though it is extremely relevant to study individual-level drivers, we need to look towards the macro-level in order to determine how specific policies, laws and societal norms affect women's risk of IPV. Using cross-national data from 40 developing countries and multi-level analysis techniques, this paper demonstrates that socio-economic development, beliefs and laws have an important impact on IPV.

This study contributes to the existing literature on IPV in at least three important respects. Firstly, only very few studies have analysed macro-level drivers of IPV in more than one country (Heise \& Kotsadam 2015; Larsen 2016). This paper provides additional evidence on the macro-level drivers of IPV using cross-national survey data. Secondly, this paper contributes to a small but growing literature on IPV in developing countries (see Stoeckl et al. 2014; Devries et al. 2010). Lastly, this study examines a set of macro-level drivers that have not been analysed before. The most comprehensive study on macro-level drivers of IPV was recently conducted by Heise and Kotsadam (2015), who focus their analysis on gender-related factors such as women's economic and political participation and gender inequality. However, this paper is the first to provide an in-depth analysis of the effect of religion and 
institutions on IPV.1

The paper is organised as follows. Section 2 provides a justification for why specific macro-level drivers were selected for the analysis. Section 3 gives an overview of the data and methods used in this study. Section 4 presents evidence on the prevalence of IPV in the sample of 40 developing countries. Section 5 presents the results. Section 6 provides a discussion and section 7 concludes the paper.

\section{IPV and Macro-level drivers}

There is a small but growing literature on the macro-level drivers of IPV. The majority of studies focus on the effect of community and neighbourhood characteristics, frequently in the context of cities in the USA (Vanderende et al. 2012; Beyer et al. 2013). This literature has analysed the impact of a large set of community-level drivers including community gender norms, socio-economic standing, violence and social disorganization (Caetano et al. 2010; Browning 2002; Jain et al. 2010).

This paper analyses the impact of three macro-level drivers on IPV: socio-economic development, religion and institutions. Previous research has identified all three drivers as important determinants of other types of inter-personal and communitylevel violence, and, a priori, all three drivers also have a plausible link to IPV.

It is plausible to assume that women living in countries with high levels of socioeconomic development experience less IPV (Dollar \& Gatti 1999). However, we have little empirical evidence about this relationship. In particular, the question of how average levels of wealth and education in a country affect women from different backgrounds remains unexplored in the literature. This paper seeks to fill this gap in the literature by systematically examining the link between levels of wealth at the macro and individual-level.

Similarly, some scholars have suggested that religion and its interaction with state power plays an important role in explaining IPV (Douki et al. 2003). However, to date, these arguments have not been examined systematically. For example, it is unclear whether religion still plays a role in explaining individual women's risk of experiencing IPV once other factors such as wealth and education are controlled for.

Lastly, from a theoretical perspective, laws should also have an important impact on IPV. Becker (1968) famously argued that criminal acts (like all other behaviour) are the result of rational decision-making based on a cost-benefit analysis, where costs equal whatever penalties are imposed. Even though contemporary research focuses more on the sociological aspects of crime perpetration, many economists still work with the assumption that high penalties can deter crimes (see e.g Fajnzylber et al. 
2002). In fact, several scholars find that penalties reduce crime rates (Levitt 1995; Braga \& Weisburd 2011). Furthermore, the assumption that people change their behaviour in response to what they see happening to others who break the law, is theoretically plausible. However, the empirical evidence about the effect of legislation on IPV risk is extremely scarce.

\section{Data and Methods}

\subsection{Data}

The dataset used in this study has a two-level hierarchical structure, meaning that the data are organised both at the individual and at the country-level. The individual-level dependent variable used is binary and indicates whether a woman has experienced any form of IPV (physical, sexual or emotional) in the year preceding the interview.

Data for the individual-level dependent variable come from the Demographic and Health Surveys (DHS). The DHS are nationally representative household surveys that provide data on a large range of health-related topics. Even though the DHS surveys were not primarily designed to measure IPV, implementing agencies invest considerable effort to collect data in accordance with WHO guidelines on violence research (see Ellsberg \& Heise 2005). Only women who have completed specialised training conduct interviews on IPV. Furthermore, interviews are always carried out in private and were interrupted if privacy could not be ensured (Devries et al. 2010).

For the purpose of this study, the author obtained access to all DHS surveys that included the Domestic Violence Module and that were coded in Phase V or Phase VI. 2 This adds up to a total of 40 countries from all world regions, 3 with data collected between 2005 and 2013. Overall, 316,451 women completed the Domestic Violence Module in the 40 sampled countries. The DHS surveys distinguish between physical, sexual and emotional IPV. All of these forms of violence are captured via a series of interview questions that refer to specific acts like kicking, slapping, forcing women to have intercourse or humiliating them in front of others. Respondents who indicated that any one of these specific acts of violence occurred within the year preceding the interview, were coded as having experienced IPV.

Data for individual-level control variables also come from the DHS. All models control for women's education, women's age, childlessness, household wealth quintile (DHS wealth index), women's attitudes towards IPV, partner education, partner age and living in an urban area (see Table 1 for details). All of these variables have been identified as important individual-level drivers of IPV in previous research (Jewkes 2002; Stoeckl et al. 2014).

Data for country-level explanatory variables were collected from a range of different sources (see Table 1). The variables of interest are country-level education (the 
proportion of women in the country with tertiary education), GDP per capita, religion (a categorical measure of the dominant religion in the country) and legislation on IPV (a binary measure indicating whether or not legal provisions are in place).

[Table 1 near here]

\subsection{Methods}

This paper analyses the macro-level drivers of IPV using multi-level logistic regression models. Logistic multi-level analysis is the most suitable estimation technique when faced with a binary dependent variable in a hierarchical dataset, as is the case here. As a reminder to readers who are not familiar with this estimation technique, a coefficient in one of these models shows the effect of a one unit change in $\mathrm{x}$ on the $\log$ odds that $\mathrm{y}=1$, after holding group effects constant.

All models have a two-level structure, with individuals (at level 1) nested in countries (level 2) and control for the same set of individual-level variables (see Table 1). Data are not weighted, given that DHS weights are country-specific4 and the DHS does not provide weights that are appropriate for multi-level analysis.

All models are random-intercept logistic regression models and take the following basic form:

$$
\log (I P V)=\beta_{0}+\beta_{1}(\text { Micro Level })_{i j}+\beta_{2}(\text { Macro Level })_{j}+u_{j}+e_{i j}
$$

\section{Prevalence of IPV}

Data from this study indicates that $27.15 \%$ of women who are currently in a relationship have experienced some form of violence from their intimate partners in the last 12 months5. It is important to keep in mind that this binary measure of IPV includes different types of violence (physical, sexual and emotional) that are very different in terms of severity, frequency and impact on women's health and wellbeing (see Scott-Storey 2011).

\section{[Table 2 near here]}

Prevalence of IPV differs substantially between countries in the sample, and ranges from $9.17 \%$ in Comoros to $47.36 \%$ in Zambia. On average, approximately $19 \%$ of women have experienced physical violence, $18 \%$ have experienced emotional 
violence and $7 \%$ have experienced sexual violence in the year preceding the interview (see Table 2).6

\section{Results}

This section presents evidence on the influence of country-level socio-economic development, beliefs and institutions on IPV. It provides further support for the argument that macro-level drivers play an important role in explaining IPV in the developing world, even when individual-level factors are taken into account.

\subsection{Socio-Economic Development}

Model 1 (Table 3) indicates that women living in countries with a higher level of GDP are significantly less likely to experience IPV (see Model 1). For a woman with average 7 age and education, who lives in a middle-income household with a partner with average characteristics, the probability of experiencing IPV lies at $30.8 \%$ in a country with a GDP per capita of USD 300. In comparison, for a woman with the same characteristics, IPV risk lies at $27.6 \%$ in a country with a GDP per capita of USD 600. However, the effect of GDP on IPV appears to be inconsistent. As soon as the overall percentage of women who have attended university is included in the analysis, the relationship is no longer significant (see Model 2).

Model 3 shows the impact of country-level wealth on women from different wealth quintiles by including an interaction between the wealth of the household that women live in and the country-average of people living in the highest wealth quintile. In order to make sense of this cross-level interaction, marginal effects need to be considered. Figure 1 shows the marginal effects of a change in the proportion of women living in the richest quintile. We can draw three conclusions from this interaction.

Firstly, all women, regardless of the wealth of the household they live in, experience additional protection as the proportion of wealthy women in their country increases. Secondly, this relationship is stronger for wealthier women. In fact, the relationship is strongest for women living in the wealthiest quintile of households. Thirdly, as the proportion of wealthy women increases in a country, household wealth starts to matter more for IPV. In countries where less than $15 \%$ of households are in the wealthiest quintile, confidence intervals for individual-level wealth quintiles overlap. This indicates that all women, regardless of household wealth, experience a similar protective effect. However, as the proportion of rich women increases in a country, women who live in rich households experience a marginal protective effect that is significantly stronger than for women living in poor households. In other words, the protective effect of wealth starts to differ more strongly across households.

Model 2 and 4 analyse the influence of country-level educational indicators on IPV. 
Model 2 indicates that there is no evidence that the percentage of women who completed tertiary education is directly related to individual women's risk of IPV. However, as shown in Model 4, the impact of country-level education on IPV appears to depend on women's individual level of education. Figure 2 shows the marginal effect of the percentage of women in a country who have tertiary education (see Model 4). There are again three conclusions we can draw from this cross-level interaction.

Firstly, as the percentage of women who have completed tertiary education increases, the likelihood that a woman will experience IPV decreases. Secondly, this relationship is much stronger for poorly educated women. Holding all other factors constant, the likelihood of experiencing IPV for women with tertiary education is $4 \%$ higher in countries where $10 \%$ rather than $60 \%$ of women have tertiary education. In contrast, for women with only primary education, the difference in IPV risk between these two scenarios lies at $16.9 \%$. This indicates that poorly educated women benefit much more from being surrounded by many well-educated women than their bettereducated counterparts. Lastly, as the overall percentage of women with tertiary education increases, women's own educational background appears to matter less. In a country where $10 \%$ of women have been to university, the marginal effect differs strongly between women with different education levels. However, once approximately $25 \%$ of women in the country have completed tertiary education, the marginal effect does not differ by level of education.

[Figure 1 near here]

[Figure 2 near here]

\subsection{Religion}

As shown in Model 5 (Table 4), there is no significant difference in terms of IPV risk between majority-Christian and majority-Hindu countries as well as between majority-Christian countries and countries in the residual category (Traditionalist and Buddhist).

However, there is a relatively large and significant difference between majorityChristian countries and majority-Muslim countries. 8 Women living in Muslim countries appear to be less likely to experience IPV than women living in predominantly Christian societies. For a woman with the same characteristics, IPV risk lies at $30 \%$ if she lives in a majority Christian country, as compared to only $18.7 \%$ if she lives in a majority Muslim country.

\subsection{Institutions}

The evidence presented in Model 6 indicates that women are less likely to experience violence in countries where legal provisions against IPV are in place. For women 
living in countries with legal provisions addressing IPV, the odds of experiencing abuse are $39.2 \%$ lower than for women living in countries where no such provisions exist.

The influence of laws on women's risk of IPV appears to interact strongly with individual women's level of education as well as the level of education of their partners. Model 7 shows that ceteris paribus 9 for women with only primary education (4 years), the predicted probability of experiencing IPV is not affected by the existence of legal provisions on IPV. However, as individual women become more educated, the gap between the likelihood of experiencing IPV in countries where legal provisions do and do not exist grows larger (see Figure 3). For women with secondary education ( 8 years), this gap amounts to $16 \%$. For women with tertiary education (12 years), the gap increases even further, to $22.3 \%$.

Similarly, Model 8 shows that the effect of laws is much larger for certain groups of men. For men with only 5 years of education, the likelihood of perpetrating IPV (as reported by their female partners) does not differ between countries that do and do not have legal provisions on IPV. However, laws seem to play a much larger role as individual men become more educated (see Figure 3). The effect of laws amounts to $13 \%$ for men with secondary education (8 years) and $18 \%$ for men with tertiary education (12 years).

[Figure 3 near here]

\section{Discussion}

\subsection{Socio-Economic Development}

The evidence suggests that there is no direct relationship between GDP per capita and individual-level risk of IPV. This paper found that GDP per capita is only associated with lower levels of IPV if country-level education is excluded from the analysis. Previous research (Heise and Kotsadam, 2015) also found that GDP only has an effect on IPV when measures about social norms are excluded from the analysis. Hence, it seems as though GDP per capita is merely correlated with other social processes (such as changing levels of education and attitudes) that have an impact on IPV.

The evidence on marginal effects allows us to disaggregate the impact of socioeconomic development on individual women's risk of IPV. The results in relation to economic development suggest that, as countries become more prosperous, women from all backgrounds are marginally more protected. However, this effect is strongest for the wealthiest women. Furthermore, individual-level differences in wealth start to matter more as the proportion of wealthy women increases. The opposite is the case for education. As the proportion of highly educated women grows, all women are less 
likely to experience IPV. In particular, women with low levels of education appear to benefit most. Moreover, as the proportion of university-educated women grows, women's individual levels of education start to matter less for IPV.

The evidence indicates that both large proportions of wealthy women and highlyeducated women decrease individual women's risk of IPV. However, while wealth seems to amplify already existing differences between women from different backgrounds, education seems to act as an equalising force that plays down the effect of initial inequalities.

The differential effects of wealth and education could be explained by the fact that increasing levels of wealth may create demand for certain kinds of services such as better policing, which decreases IPV may risk. However, these services are likely to be primarily available to wealthy women and create little additional protection to those with less purchasing power. In contrast, education may lead to a change in societal norms and attitudes once there is a critical mass of educated women. Unlike large numbers of wealthy women, the existence of this critical mass of educated women might have an effect that goes beyond individuals and transforms society as a whole. Nonetheless, further research is needed to determine the specific mechanisms that could explain this relationship. In this respect, the literature on the substantive representation of women in decision-making bodies might be a good starting point (see Ruedin 2012). Moreover, the question of how social policy can be used to mitigate the effect of wealth and amplify the impact of education on IPV needs to be addressed in future research.

\subsection{Religion}

The results suggest that a woman with the same characteristics is $11.3 \%$ more likely to experience IPV in a majority-Christian country, as compared to a majority-Muslim country. How can we explain this finding? One possible explanation would be that women in majority-Muslim countries are simply more reluctant to report that they have been victims of domestic abuse than women living in majority-Christian countries. However, even though reporting rates are likely to be influenced by cultural and institutional factors, one needs to keep in mind that the dataset used for this study is exclusively made up of developing countries. Hence, we are not comparing the experiences of women living in Saudi Arabia with those living in Sweden. Instead, it is a comparison between women living in Zimbabwe, Uganda or Haiti and women living in Jordan, Bangladesh or Kyrgyzstan. Even though we cannot completely reject the possibility, we have little reason to believe that women living in the latter set of countries are significantly less likely to disclose IPV than women in the former set of countries.

Instead, one could argue that the level of alcohol consumption is the most relevant difference between Christian and Muslim countries, and speculate that it could be the 
main reason behind different levels of IPV. As was shown in numerous other studies, men who consume alcohol are significantly more likely to be violent towards their female partners than men who do not (Stoeckl et al. 2014; Jewkes 2002). In Christian countries, more than $61 \%$ of women who are currently in a relationship indicated that their partners consume alcohol in comparison to only $12 \%$ in majority-Muslim countries. Similarly, 64\% of those women in Christian countries indicated that their husbands get drunk often, as compared to only $10 \%$ in Muslim countries. These findings are in line with previous studies that found reported alcohol consumption to be significantly lower in majority-Muslim countries (see Clausen et al., 2009). Unfortunately, the influence of alcohol consumption on IPV cannot be tested directly on this sample of countries, given that for one quarter of Muslim countries, the DHS did not include questions about alcohol consumption. Further research on the interaction between religion, alcohol consumption and IPV is needed to substantiate and explain the relationship found in this study.

\subsection{Institutions}

The evidence suggests that women living in countries in which legal provisions on IPV exist are much less likely to experience IPV than their counterparts living in countries where no such provisions are in place. In fact, the odds of experiencing IPV are almost $40 \%$ lower. This finding is in line with previous evidence on the impact of the legal system on IPV. For example, on a sample of developed and developing countries, Heise and Kotsadam (2015) for example find that gender-based discrimination related to land-access increases women's risk of IPV.

Some might argue that laws are generally a reflection of prevailing social norms and that a causal relationship between laws and IPV cannot be inferred from the evidence presented above. However, social norms about the acceptability of IPV as well as decision-making in the household were controlled for in the analysis. Hence, even though we cannot fully exclude the possible that social norms are the underlying driver, the analysis suggests that laws can an impact on IPV even when attitudinal factors are taken into account.

The evidence also shows that there is a relationship between laws on IPV and the level of education of women and their partners. Highly educated women are much more protected in countries where laws on IPV exist than their badly educated counterparts. Similarly, highly educated men are much less likely to perpetrate IPV in

countries where legal provisions are in place than men with only few years of education.

These findings make intuitive sense. It is well known that not all women are equally able to make use of legislation on IPV. Uneducated and disadvantaged women living in remote areas might simply not be aware that such legislation exists. Furthermore, even if they would know about its existence, they might not have the resources to 
follow through with legal proceedings (Kovacs et al. 2013). Hence, it should come as no surprise that for disadvantaged women, the existence of laws does not make much of a difference given that they cannot access the legal system. Similarly, men with low levels of education are less likely to know about the existence of domestic violence legislation or might be less able to understand its consequences. Hence, they are less likely to change their behaviour in response.

Both of these findings are highly relevant for policy makers. The evidence from this study indicates that legal provisions on IPV make no difference to women with only primary education. This strongly suggests that, in order to make IPV laws work in practice, policy makers need to ensure that people from different backgrounds can access the legal system. Similarly, the finding that only men who surpass secondary education are less likely to perpetrate violence in countries with laws against IPV underlines the important link between knowledge and deterrence. If a deterrence effect exist, both potential victims and possible perpetrators need to be made aware of such legislation.

\subsection{Limitations}

This study is limited in several respects. Firstly, most studies that analyse macro-level drivers of IPV (Caetano et al. 2010; Browning 2002; Jain et al. 2010) employ a much finer geographical scale (community, neighbourhood) than the one used in this paper. This means that they are able to identify heterogeneity that is masked at the countrylevel. Unfortunately, given limited data availability of contextual variables, this study does not disaggregate findings down to the community-level. However, this paper provides evidence that applies more broadly to a larger geographical area. Furthermore, it estimates the impact of highly policy-relevant drivers like legal provisions that typically apply to the national-level rather than the community-level.

Secondly, this study does not address potential endogeneity issues, for example, regarding the interactive relationship between GDP per capita and IPV. Potentially endogenous relationships between presumed drivers of IPV should be explored in more detail in future research. Lastly, this paper also does not address the potential issue of disclosure rates varying non-randomly between countries. This issue applies to most surveys carried out in more than one country and further research is needed to evaluate the magnitude of the potential bias.

\section{Conclusion}

This paper has put forward a number of arguments about the macro-level drivers of IPV in developing countries. Overall, it advanced the argument that if we want to understand why women experience IPV, we need to look beyond the usual, individual-level drivers of violence. Women, and the violence they experience, do not exist in a vacuum. They exist in a society with a certain level of socio-economic 
development, with specific laws and dominant beliefs. This study has shown that these factors play an important role in explaining IPV.

This paper provided evidence which suggests that women living in countries with a higher level of socio-economic development experience IPV less frequently. Importantly, it also showed that wealth and education at the country-level interact with women's own socio-economic background and that while wealth can amplify already existing inequalities, education acts as an equalising force. Furthermore, it demonstrated that religion at the country-level plays an important role in explaining individual women's exposure to IPV. Women living in majority-Muslim countries experience significantly less IPV than their counterparts living in countries where Christianity is the dominant religion. Lastly, this paper argued that institutions matter for explaining IPV. It found that women living in countries with laws prohibiting domestic abuse experience significantly less violence than women living in countries where these laws do not exist. Furthermore, it provided evidence that the impact of laws differs strongly by the level of education of women and their partners.

[Table 3 near here]

[Table 4 near here]

\section{Disclosure Statement}

The author reports no financial interests or potential conflicts of interest arising from this research. 


\section{References}

Abramsky, T. et al., 2011. What factors are associated with recent intimate partner violence? findings from the WHO multi-country study on women's health and domestic violence. BMC public health, 11(1), p.109.

Beyer, K., Wallis, A.B. \& Hamberger, L.K., 2013. Neighborhood environment and intimate partner violence: a systematic review. Trauma, violence \& abuse, 16(1), pp.16-47.

Braga, A.A. \& Weisburd, D.L., 2011. The effects of focused deterrence strategies on crime: A systematic review and meta-analysis of the empirical evidence. Journal of Research in Crime and Delinquency.

Browning, C.R., 2002. The Span of Collective Efficacy: Extending Social Disorganization Theory to Partner Violence. Journal of Marriage and Family, 64(4), pp.833-850.

Caetano, R., Ramisetty-Mikler, S. \& Harris, T.R., 2010. Neighborhood characteristics as predictors of male to female and female to male partner violence. Journal of interpersonal violence, 25(11), pp.1986-2009.

Campbell, J. et al., 2002. Intimate partner violence and physical health consequences. Archives of internal medicine, 162(10), pp.1157-1163.

Collier, P., Bank, W. \& Hoeffler, A., 2002. Greed and Grievance in Civil War.

Devries, K.M. et al., 2010. Intimate partner violence during pregnancy: analysis of prevalence data from 19 countries. Reproductive Health Matters, 18(36), pp.158-170.

Dollar, D. \& Gatti, R., 1999. Gender inequality, income, and growth: are good times good for women?, Development Research Group, The World Bank.

Douki, S. et al., 2003. Violence against women in Arab and Islamic countries. Archives of Women's Mental Health, 6(3), pp.165-171.

Ellsberg, M. \& Heise, L., 2005. Researching violence against women: A practical guide for research and activists.

Fajnzylber, P., Lederman, D. \& Loayza, N., 2002. What causes violent crime? European Economic Review, 46(7), pp.1323-1357.

Garcia-Moreno, C. et al., 2013. Global and regional estimates of violence against women: prevalence and health effects of intimate partner violence and non-partner sexual violence, Geneva Switzerland World Health Organization [WHO] 2013.

Heise, L., Ellsberg, M. \& Gottemoeller, M., 1999. Ending violence against women. Population Reports. Series L: Issues in World Health, (11), pp.1-43.

Heise, L.L. \& Kotsadam, A., 2015. Cross-national and multilevel correlates of partner violence: an analysis of data from population-based surveys. The Lancet Global Health, 3(6), p.p.332-p.340.

Jain, S. et al., 2010. Neighborhood predictors of dating violence victimization and perpetration in young adulthood: a multilevel study. American journal of public health, 100(9), pp.1737-44.

Jaspard, M. et al., 2003. Les violences envers les femmes. Une enquête nationale. Paris: La documentation française.

Jewkes, R., 2002. Intimate partner violence : Causes and prevention. Lancet, 359.

Johnson, M.P., 1995. Patriarchal terrorism and common couple violence: Two forms of violence against women. Journal of Marriage and the Family, pp.283-294. 
Johri, M. et al., 2011. Increased risk of miscarriage among women experiencing physical or sexual intimate partner violence during pregnancy in Guatemala City, Guatemala: crosssectional study. BMC pregnancy and childbirth, 11(1), p.49.

Kaya, Y. \& Cook, K.J., 2010. A cross-national analysis of physical intimate partner violence against women. International Journal of Comparative Sociology, 51(6), pp.423-444.

Kovacs, R., Ndashe, S. \& Williams, J., 2013. Twelve years later: how the Recognition of Customary Marriages Act of 1998 is failing women in South Africa. In Marriage, Land and Custom: Essays on Law and Social Change in South Africa. pp. 121-146.

Larsen, M., 2016. Health Inequities Related to Intimate Partner Violence Against Women The Role of Social Policy in the United States, Germany, and Norway,

Levitt, S.D., 1995. The effect of prison population size on crime rates: Evidence from prison overcrowding litigation,

Ludermir, A.B. et al., 2008. Violence against women by their intimate partner and common mental disorders. Social science \& medicine, 66(4), pp.1008-1018.

Mouzos, J. \& Makkai, T., 2004. Women's experiences of male violence: findings from the Australian component of the International Violence Against Women Survey (IVAWS), Australian Institute of Criminology Canberra.

Parish, W.L. et al., 2004. Intimate partner violence in China: national prevalence, risk factors and associated health problems. International family planning perspectives, pp.174-181.

Pridemore, W.A., 2008. A methodological addition to the cross-national empirical literature on social structure and homicide: a first test of the poverty-homicide thesis. Criminology, 46(1), pp.133-154.

REYNAL-QUEROL, M., 2002. Ethnicity, Political Systems, and Civil Wars. Journal of Conflict Resolution, 46(1), pp.29-54.

Rodríguez-Menés, J. \& Safranoff, A., 2012. Violence against women in intimate relations: A contrast of five theories. European Journal of Criminology, 9(6), pp.584-602.

Ruedin, D., 2012. The Representation of Women in National Parliaments: A Cross-national Comparison. European Sociological Review, 28(1), pp.96-109.

Scott-Storey, K., 2011. Cumulative abuse: do things add up? An evaluation of the conceptualization, operationalization, and methodological approaches in the study of the phenomenon of cumulative abuse. Trauma, violence \& abuse, 12(3), pp.135-150.

Stoeckl, H. et al., 2014. Intimate partner violence among adolescents and young women: prevalence and associated factors in nine countries: a cross-sectional study. BMC public health, 14(1), p.751.

Vanderende, K.E. et al., 2012. Community-level correlates of intimate partner violence against women globally: A systematic review Sexual abuse Gender inequality. Social Science \& Medicine, 75(7), pp.1143-1155.

Walby, S., Allen, J. \& Britain, G., 2004. Domestic violence, sexual assault and stalking: Findings from the British Crime Survey. 


\section{Notes}

1 Kaya and Cook (2010) have attempted to analyse both of these factors. However, their analysis uses a dataset with only 40 observations and has several serious methodological flaws.

2 DHS Phases simply refer to a specific coding of the data (questions used, variable definitions and such), which has evolved over the years. The coding of earlier DHS phases is not compatible with the coding of Phase V and VI.

3 The countries included in this study are (by level of IPV, low-to-high): Comoros (2012), Philippines (2013), Burkina Faso (2010), Azerbaijan (2006), Tajikistan (2012), Cambodia (2005), Peru (2012), Nepal (2007), Colombia (2010), Ukraine (2007), Nigeria (2013), Jordan (2012), Kyrgyzstan (2012), Honduras (2011), Haiti (2012), Dominican Republic (2007), India (2006), Bangladesh (2007), Cote d'Ivoire (2012), Moldova (2005), Malawi (2010), Bolivia (2008), Pakistan (2012), Egypt (2005), Sierra Leone (2013), Zimbabwe (2007), Timor-Leste (2009), Sao Tome and Principe (2008), Ghana (2008), Mali (2012), Tanzania (2010), Kenya (2008), Mozambique (2011), Gabon (2012), Uganda (2011), DRC (2013), Rwanda (2010), Cameroon (2011), Liberia (2007) and Zambia (2007).

4 Weights for the Domestic Violence Module are normalised, meaning that they are multiplied by a normalisation factor that is country specific. Weights therefore cannot be pooled across countries.

5 This refers to the proportion of women in the sample that have experienced physical, sexual or emotional violence in the year preceding the interview.

6 The number of observations in Table 2 differs by type of violence because three countries miss a measure for emotional violence and one country misses a measure for sexual violence. ${ }_{7}$ 'Average' in the sense that all individual-level characteristics are held at their means. This average woman is also childless and lives in an urban area.

8 The sample is primarily made up of respondents from majority-Christian (46\%) and majority-Muslim countries $(26 \%)$. Hence, it is not well suited to measuring the impact of other religions.

9 All things are held equal, in the sense that all individual and country-level characteristics (except for education) are held at their means. 